\title{
Cut-off values for sufficient cortisol response to low dose Short Synacthen Test after surgery for non-functioning pituitary adenoma
}

\author{
Anders Jensen Kolnes ${ }^{1,2}$, Kristin Astrid $\emptyset$ ystese $^{1}$, Daniel Dahlberg ${ }^{3}$, Jon Berg-Johnsen ${ }^{2,3}$, Pitt \\ Niehusmann ${ }^{4}$, Jens Pahnke ${ }^{2,4}$, Jens Bollerslev ${ }^{1,2}$, Anders Palmstrøm Jørgensen ${ }^{1}$. \\ ${ }^{1}$ Section of Specialized Endocrinology, Rikshospitalet, Oslo University Hospital, Oslo, Norway; \\ ${ }^{2}$ Faculty of Medicine, University of Oslo, Oslo, Norway; ${ }^{3}$ Department of Neurosurgery, Rikshospitalet, \\ Oslo University Hospital, Oslo, Norway; ${ }^{4}$ Department of Neuro-/pathology, Oslo University Hospital, \\ Oslo, Norway.
}

\section{Correspondence:}

Anders Kolnes Jensen

Section of Specialized Endocrinology,

Oslo University Hospital, and Faculty of Medicine,

University of Oslo,

Oslo, Norway

a.j.kolnes@studmed.uio.no

\section{Acknowledgements}

We thank Kari Abelsen and Ansgar Heck for assistance and support. This study was based on routine practice at the Section of Specialized Endocrinology, Rikshospitalet, Oslo University Hospital in Oslo, and did not receive additional funding. 


\section{Abstract}

Objective: The aim was to study the prevalence of secondary adrenal insufficiency before and after surgery for non-functioning pituitary adenomas, as well as determine risk factors for developing secondary adrenal insufficiency. A secondary aim was to determine adequate $p$-cortisol response to a $1 \mu \mathrm{g}$ Short Synacthen Test after surgery.

Design: Longitudinal cohort study.

Methods: 117 patients (52/66 females/males, age 59 years) undergoing primary surgery for clinically non-functioning pituitary adenomas were included. P-cortisol was measured in morning blood samples. Three months after surgery a Short Synacthen Test was performed.

Results: All tumours were macroadenomas (mean size $26.9 \mathrm{~mm}$, range 13-61 mm). The surgical indications were visual impairment (93), tumour growth (16), pituitary apoplexy (6) and headache (2). Before surgery, $17 \%$ of the patients had SAI, decreasing to $15 \%$ three months postoperatively. Risk of SAI was increased in patients operated for pituitary apoplexy $(p<0.001)$, while age, sex, tumour size, and complication rate were not different from the remaining cohort. Three months after surgery, all patients with baseline $\mathrm{p}$-cortisol $\geq 172 \mathrm{nmol} / \mathrm{l}(6.2 \mu \mathrm{g} / \mathrm{dl})$ and peak p-cortisol during Short Synacthen Test $\geq 320 \mathrm{nmol} / \mathrm{l}(11.6 \mu \mathrm{g} / \mathrm{dl})$ tapered cortisone unproblematically. In patients with intact hypothalamic-pituitary-adrenal-axis, p-cortisol peaked $<500 \mathrm{nmol} / \mathrm{l}(18.1 \mathrm{\mu g} / \mathrm{dl})$ during Short Synacthen Test in $48 \%$ of patient.

Conclusion: Pituitary surgery is safe and transsphenoidal surgery rarely causes new SAl. Relying solely on morning $p$-cortisol for diagnosing secondary adrenal insufficiency gives false positives and the Short Synacthen test remains useful. A peak p-cortisol $\geq 320$ during $(11.6 \mu \mathrm{g} / \mathrm{dl})$ Short Synacthen test indicates a sufficient response, while $<309 \mathrm{nmol} / \mathrm{l}(11.2 \mathrm{\mu g} / \mathrm{dl})$ indicates secondary adrenal insufficiency.

Keywords: non-functioning pituitary adenoma; Short Synacthen Test; secondary adrenal insufficiency; pituitary surgery 


\section{Introduction}

Pituitary adenoma's (PA) account for 10 - 15\% of all primary brain tumours, and non-functioning pituitary adenoma's (NFPA) are the most common subtype accounting for $43-54 \%$ of the PA's [2, 28]. NFPA's without clinical or biochemical signs of hormone overproduction are usually benign and slow growing tumours. As a consequence of suprasellar growth and compression of anterior visual pathways visual impairment is a common symptom [12]. Some patients present with acute symptoms due to pituitary apoplexy, evolving symptoms of local mass effect or hypopituitarism [12]. When the tumour is incidentally found on imaging, surgery is usually postponed until the patients develop symptoms or the tumour approaches the optic chiasm. Beyond hormonal substitution there is no wellestablished medical treatment for NFPA's [16].

Patients with pituitary adenomas are at an increased risk for hypopituitarism, as well both pre- as postoperatively $[27,14,29,12]$. Hypopituitarism is associated with increased mortality, morbidity and also quality of life $[10,14,29]$. The integrity of the HPA (hypothalamus-pituitary-adrenal) axis is particularly important, as is the correct diagnosis of secondary adrenal insufficiency (SAI) $[7,26]$ However, as glucocorticoid use may have adverse effects, unnecessary replacement therapy should be avoided $[15,20,31]$.

SAl is common in patients with NFPAs, and the frequency preoperatively has been reported to be 22 $53 \%[13,25,6,18,30,11]$. After surgery recovery from SAl occurred in $16-62 \%$ of the patients $[6,13]$, while the development of new SAI ranged from $1 \%-44 \%$, making the prevalence of SAI after surgery to be $18-60 \%[13,25,6,18,30]$.

The insulin tolerance test (ITT) and the Short Synacthen Test (SST) can be used for evaluation of the HPA axis and have been shown to be well correlated $[1,17,23]$. When performing the SST, both a high $(250 \mu \mathrm{g})$ and a low dose $(1 \mu \mathrm{g})$ can be used, and they yield similar results $[1,17,24]$. Previous studies have shown that $\mathrm{p}$-cortisol peaks around 30 minutes during the low dose SST, but some centres perform a 60 minute test $[1,17,24]$.

The aim of this study was to investigate surgery's ability to rescue the HPA axis function in patients with NFPA's, and potential risk factors for developing new SAI after surgery. Further, the laboratory methods for analyses of $p$-cortisol have changed to more specific assay in the recent years, while the normal cut-off values for SST was defined decades ago. We therefore also aimed to define new cut-off values for a normal cortisol response in this population.

We hypothesized that (i) endoscopic transsphenoidal surgery rescues the hypothalamic-pituitaryadrenal (HPA) axis in most patients with NFPA; (ii) pituitary apoplexy is the main cause for 
postoperative SAI; (iii) medical history and basal hormone values renders SST unnecessary to diagnose SAI. 


\section{Material and methods}

A total of 117 patients operated for a clinical NFPA were prospectively included in this study between December 2014 and October 2018. Inclusion criteria were: (1) patients above 18 years of age undergoing surgery for pituitary adenoma; (2) no clinical or biochemical signs of hormone overproduction; (3) no previous surgery or radiation to the pituitary gland. Prior to surgery the patients underwent clinical and biochemical evaluation, either at the Department of Endocrinology, Oslo University Hospital (OUS), or in the referring hospital.

All patients had a sellar tumour on radiologic examination (116 by MRI and 1 by CT). Routine radiology reports were used when describing tumour size. Neuropathologists confirmed the diagnosis of pituitary adenoma in 113 patients using routine stains (H\&E, reticulin, immunohistochemical stains). In four cases (3\%) the specimen was necrotic, but diagnosis of pituitary adenoma was most likely Immunohistochemical analyses showed expression of $\mathrm{FSH} / \mathrm{LH}$ in $62 \%$, ACTH in $9 \%$, TSH/GH/prolactin in $6 \%$, while $20 \%$ adenomas were hormone staining negative, respectively. We did not perform immunohistochemical analyses for transcription factors in this study. Fourteen patients operated on a suspicion of NFPA were not included in the study due to another histopathological diagnosis.

Routine follow-up visit was scheduled three months postoperatively, with clinical evaluation, hormonal analyses, and MRI of the pituitary region. 104 patients attended follow-up at the Department of Endocrinology OUS, while thirteen patients attended follow up at their local hospital.

HPA axis was evaluated by morning p-cortisol in blood samples taken between 08.00 and 10.00 both pre- and postoperatively. Preoperative SAI was defined as low morning $\mathrm{p}$-cortisol in the presence of symptoms of hypocortisolism and/or improvement of symptoms with glucocorticoid therapy. Patients that underwent pituitary apoplexy who were given glucocorticoids before p-cortisol was measured were classified as having SAI.

On discharge from the hospital after surgery, the decision to substitute patients with glucocorticoids was made by the attending neurosurgeon or endocrinologist. In the cases where substitution was given, cortisone acetate was used in doses of 12.5 - $37.5 \mathrm{mg}$ daily.

At the three month follow up, fasting morning samples were taken and a $1 \mu \mathrm{g}$ SST was performed in 99 patients. Before p-cortisol measurements, patients had abstained from cortisone since 15.00 the previous afternoon. The decision to continue cortisone substitution was then made by the evaluating clinician, based on clinical signs and biochemical results. The study did not interfere with this decision. Patients in whom cortisone was continued following the visit were referred to as having SAl, and those where it was tapered as not having SAI. 
For 92 patients, SST test was performed with $1 \mu \mathrm{g}$ (low dose) Synacthen (Synacthen, Alfasigma, Milan, Italy), while $250 \mu \mathrm{g}$ (high dose) was used in seven patients followed at their local hospital. The Synacthen was injected intravenously in all patients. Samples were collected immediately before injection, then 30 and 60 minutes thereafter. ITTs were performed in four patients with infusion of insulin until hypoglycaemia was reached $(<2.2 \mathrm{mmol} / \mathrm{l})$ before $\mathrm{p}$-cortisol was measured.

Plasma-cortisol was analysed by electrochemiluminescence assay on Roche Modular E170 (Roche Diagnostics, Rotkreuz, Switzerland) until 23.05.2016, and after by Roche Cobas e602. A single hospital used Roche Cobas e801 for measuring p-cortisol in 13 patients in the follow-up period. The reference range was not affected by the change of platform. From 01.09.15 the cortisol assay changed from a polyclonal to a monoclonal antibody. The new assay is more specific for cortisol and has reference range $112-502 \mathrm{nmol} / \mathrm{l}(4.1-18.2 \mu \mathrm{g} / \mathrm{dl})$, while the old assay had reference range 138-690 nmol/l (5.0$25.0 \mu \mathrm{g} / \mathrm{dl}$ ). The coefficient of variation was $<5.5 \%$ for both methods.

The other pituitary axes were evaluated using standard laboratory methods and the laboratory's reference values. Secondary hypothyroidism was diagnosed by free-T4 below reference interval in the presence of low or normal TSH. TSH-insufficiency could not be diagnosed in patients with known disease of the thyroid gland.

Hypogonadotropic hypogonadism was defined as testosterone below reference interval associated with low or normal gonadotropins in males. In postmenopausal females gonadotropins inappropriately low for age (FSH <15 IU/I, LH <8 IU/I) was used. In premenopausal females hypogonadism was defined as amenorrhea, and/or low gonadotropins associated with low oestrogen.

We used values of IGF-1 as an indication of growth hormone deficiency. Age and gender specific lower limit of normal IGF-1 levels for each of the patients was used as cut-off. Dynamic testing of growth hormone was not performed routinely at the three months follow-up.

Patients in need of vasopressin for polyuria and hypernatremia were categorized as having diabetes insipidus (DI). DI was considered transient if vasopressin was tapered and urine output and sodium concentration normalized. Persistent DI was defined as continued polyuria and use of vasopressin. None of the patients performed an over-night water deprivation test.

Statistics: Continuous data were analysed by Students t-test if normally distributed, otherwise Mann Whitney U-test was performed. Chi-squared test was used for comparison of categorical variables. Values are given as mean \pm standard deviation and $\mathrm{P}<0.05$ was considered significant. Statistical analyses were performed using SATA version 15.1. All patients gave signed informed consent and the study was approved by the regional Ethics Committee. 


\section{Results}

\section{Surgery}

The operations were performed in a single tertiary referral centre, OUS, from December 2014 to October 2018. Two surgeons performed the majority of the operations (103), while other two surgeons performed the remaining 14. All tumours were macroadenomas (Table 1). An endoscopic transsphenoidal approach was used in 114 patients, while three patients were operated by craniotomy. Indications for surgery were visual impairment in 93, tumour growth and elevated/compressed optic chiasm in 16, pituitary apoplexy in 6 and typical headache in 2 patients. All patients with pituitary apoplexy had affected vision.

Vision improved in 77 (87\%) of 89 patients, remained unchanged in eleven, and worsened in a single patient following surgery. Visual status after surgery was lacking in 10 patients.

\section{Complications}

No complications were described in 98 patients. In the early phase after surgery, 23 complications developed in 19 patients (Table 2). Cerebrospinal fluid leakage included patients with reoperation or lumbar drainage with positive $\beta$-trace. Three patients developed haemorrhage (two after transcranial surgery), all of whom were re-operated with evacuation of a postoperative hematoma. Meningitis was not seen in any of the patients.

\section{Secondary adrenal insufficiency}

Before surgery, SAI was diagnosed in 20 (17\%) patients based on clinical evaluation and early morning plasma-cortisol values. There was no significant difference in tumour size, age or sex among patients with and those without SAI, neither pre- nor postoperatively (Table 3). All patients with preoperative SAl were operated through the transsphenoidal approach.

Upon discharge from the hospital, 76 patients (65\%) were substituted with cortisone and remained on cortisone until the three-month evaluation. No patient in the cohort underwent secondary surgery or irradiation within three months and all (117) came to the follow-up visit.

At the three-month postoperative visit, 17 patients (15\%) were diagnosed with SAl, twelve of which had preoperatively SAI. Of the five patients who developed a new SAI, two were operated with open transcranial approach. There was no difference in age, tumour size, complications or sex among those with and without SAI, neither pre- nor postoperatively.

Eight of the twenty patients with preoperative SAI recovered function of the HPA axis by surgery. Age, sex, tumour size, and complication rate, was not different between patients who recovered from SAI 
versus those who did not (data not shown). Neither did analysis of the five patients who developed SAl after surgery show any difference from the remaining cohort with respect to age, sex, tumour size or complications (data not shown).

Six patients underwent transsphenoidal surgery for pituitary apoplexy (headache, nausea, visual impairment, and radiological findings). Pathologic examination confirmed the presence of an adenoma with bleeding in all specimens. At the three-month follow-up, five of six had SAl, indicating a significantly increased risk of developing SAl after pituitary apoplexy $(p<0.001)$.

Of the 76 patients who used cortisone in the early postoperative period, 59 patients were weaned off cortisone substitution at three-month visit. After tapering of cortisone, cortisone had not been reinstated in any patient, nor had any patient been hospitalized due to hypocortisolism. The shortest follow up of any patients who tapered cortisone was $<11$ months (i.e. 8 months after discontinuing cortisone at the three-month visit). No patients developed SAI after three-months visit (shortest follow-up 8 months).

\section{Cut-offs for $1 \mu \mathrm{g}$ SST}

The new monoclonal cortisol assay was used for measuring early morning cortisol in 92 patients, and a low dose SST was performed in 82 of these. In addition, thirteen patients underwent high dose test or were tested using the old assay. There was no significant difference in $p$-cortisol (at baseline or after 30 minutes) between low and high dose tests, nor between the new and old assay (data not shown).

Only results for the low dose $(1 \mu \mathrm{g}) \mathrm{SST}$ and p-cortisol measured with the new assay are considered in the following sections ( $n=92$ for morning $p$-cortisol; $n=82$ for SST). The results of the $p$-cortisol at baseline and during to SST is shown in Figure 1 and Table 4. Of the patients without SAI, p-cortisol peaked at $<400 \mathrm{nmol}(14.5 \mu \mathrm{g} / \mathrm{dl})$ in $13 \%$ of patients and below $500 \mathrm{nmol} / \mathrm{l}(18.1 \mu \mathrm{g} / \mathrm{dl})$ in $48 \%$ of patients.

Cortisone was tapered three months postoperatively, without adverse events, in all patients with early morning p-cortisol $\geq 172 \mathrm{nmol} / \mathrm{l}(6.2 \mu \mathrm{g} / \mathrm{dl})$, or $\mathrm{p}$-cortisol $\geq 320 \mathrm{nmol} / \mathrm{l}(11.6 \mu \mathrm{g} / \mathrm{dl})$ at 30 minutes during ST. The highest baseline $\mathrm{p}$-cortisol in a patient with SAI was $168 \mathrm{nmol} / \mathrm{l}(6.1 \mu \mathrm{g} / \mathrm{dl})$ and the highest 30minute response was $309 \mathrm{nmol} / \mathrm{l}(11.2 \mu \mathrm{g} / \mathrm{dl})$ (Figure 1).

In patients without SAI the lowest baseline p-cortisol was $64 \mathrm{nmol} / \mathrm{l}(2.3 \mu \mathrm{g} / \mathrm{dl})$ and the lowest 30 minutes value was $320 \mathrm{nmol} / \mathrm{l}(11.6 \mu \mathrm{g} / \mathrm{dl})$. Thus, the baseline $\mathrm{p}$-cortisol of the two groups overlapped, whereas the peak $p$-cortisol response during SST did not. Four patients without SAI had baseline $p$ - 
cortisol $<168 \mathrm{nmol} / \mathrm{l}(6.1 \mu \mathrm{g} / \mathrm{dl})$ but considered to have normal HPA axis after ST, indicating that SST remained useful.

Other pituitary axes

Hypopituitarism of one or more axes was diagnosed in 83 patients (71\%) prior to surgery, of which 22 patients (27\%) recovered (Table 5). Preoperatively, hypopituitarism was diagnosed in one axis in 49 patients, while 21 had insufficiency of two axes, 12 of three axes, and one patient had insufficiency of four axes. In the 34 patients with normal pituitary function before surgery, new hypopituitarism was seen in four patients (12\%).

In total, hypopituitarism was seen in 65 patients (55\%) after surgery. Postoperatively, 31 patients had insufficiency of one axis, 24 patients of two axes, 7 patients of three axes, 2 patients of four axes, and a single patient had deficiency of all five pituitary axes. The average number of axes with insufficiency was 1.1 before surgery and 1.0 after surgery $(p=0.48)$ (Table 4$)$. Patients with SAI had failure of significantly more pituitary axes compared to patients without SAI, both pre- $(2.4 \pm 0.8$ vs $0.9 \pm 0.8$, $p<0.001)$ and postoperatively $(1.8 \pm 1.0$ vs $0.8 \pm 1.0, p<0.001)$. The number of failing pituitary axes were not significantly associated with age, sex, nor tumour size.

Three months after surgery, all patients who had SAI also developed failure of at least one additional pituitary axis. In the four patients with p-cortisol $<168 \mathrm{nmol} / \mathrm{l}(6.1 \mu \mathrm{g} / \mathrm{dl})$ that did not have SAl, three patients had insufficiency of other axes (1, 2 and 3 axes, respectively), while one patient had entirely normal pituitary function. 


\section{Discussion}

In the present prospective study of patients with NFPA, we demonstrated that a large proportion of patients with preoperative SAI recovered by surgery and that the majority of patients who developed SAI had undergone pituitary apoplexy or were operated by a transcranial procedure. Thereby, transsphenoidal surgery of NFPA was an uncommon cause of new SAI. We demonstrate that an early morning $\mathrm{p}$-cortisol $>168 \mathrm{nmol} / \mathrm{l}(6.1 \mu \mathrm{g} / \mathrm{dl})$ or $\mathrm{p}$-cortisol $\geq 320 \mathrm{nmol} / \mathrm{l}(11.6 \mu \mathrm{g} / \mathrm{dl})$ following SST indicates a sufficient function of the HPA axis.

The prevalence of SAI pre - and postoperatively in our cohort was similar to the rate reported in other studies (13-53\%) $[3,8,9,11,13,21,22,25]$. Development of SAI after surgery has been reported to be from $1-7.5 \%[9,13,21,25]$. In accordance with the present study, the rate of HPA axis recovery following surgery seems to be high (21-41\%) $[9,13,25]$. While some studies report an overall decrease in SAI after surgery $[8,13,25]$, others however do report an increase $[9,11,21,22]$. The reason for this is uncertain, but may be linked to the degree of radical surgery, and the intention to completely resect the tumour. The criteria for diagnosing SAI also vary between studies, potentially influencing the reported prevalence.

Pituitary apoplexy increased the risk for SAI postoperatively in our study, as reported elsewhere [5]. However, we found no correlation between tumour size, age, sex, the surgical approach, or complications. A recent study found that postoperative SAI occurred more frequently in patients above 50 years, most common in males, in patients with CSF leak at surgery, and in patients with visual impairment at presentation [3]. In the present series, we could not confirm these findings.

Neither could we identify factors predisposing for development of or recovery from hypopituitarism after surgery. In other studies development of hypopituitarism have been associated with larger tumours, old age, and transcranial approach $[4,13,25,30]$, while recovery of hypopituitarism after surgery have been associated with young age, small tumour, and absence of CSF leak, and transsphenoidal approach $[13,25]$.

A normal response to SST has traditionally been defined as a peak value of cortisol above $500 \mathrm{nmol} / \mathrm{I}$ $(18.1 \mu \mathrm{g} / \mathrm{dl})$ [23] based on older assays. In the present study, we found that many patients with peak values below this level were not in the need of cortisone substitution. This difference seems to be best explained by the change in assay, where the new and more sensitive assay gives $15-20 \%$ lower $p$ cortisol values, however non-linear and depending on the actual cortisol level (unpublished data from Department of Clinical Biochemistry, Oslo University Hospital).

The diagnosis of SAI was not routinely confirmed by repeat SST or ITT, but by observation only. Particularly, the patients who discontinued cortisone were of interest. The majority of these patients 
have been followed for more than one year without developing new signs of hypocortisolism, indicating that the values reported here indicate a sufficient response to ST.

We speculated that in patients with low morning p-cortisol, the presence of insufficiency of other pituitary axes could be predictive of SAI and render the SST unnecessary to perform. However our data indicates that a postoperative SST is most useful to avoid unnecessary cortisol replacement therapy.

We found that hypopituitarism of one or more axes were common prior to surgery, with recovery of approximately one quarter of these by surgery. Other studies have reported rates of hypopituitarism of any axis in $80-86 \%$ prior to surgery $[11,13,25]$, decreasing to $72 \%$ three months after surgery [25]. However, only few patients recovered or developed new hypopituitarism after the three month followup [25]. The timing of recovery or new failure of HPA axis was similar in another study, where no patients developed SAI later than 3 months after surgery [22]. In accordance, no patients have developed new SAI after three months, while three had recovered at one-year visit in our study.

Of major clinical importance, the vision improved after surgery in most patients in our series. This corresponds to other series where visual status improved in $79-86 \%$ of patients after surgery, but deteriorated in $2-3 \%[11,19,22]$. Our complication rate for DI and CSF-leakage was also similar to other studies $[13,19,25]$.

\section{Limitations:}

While observation of the patients indicate that the proposed $p$-cortisol values are adequate, repeat SST or ITT could have been performed after the three-month visit.

We can't speculate on what values it's safe to leave the patients without substitutional therapy after surgery, since p-cortisol was not measured systematically upon discharge from hospital..

Although all patients attended radiological follow up after surgery, the images were not systematically evaluated for residual tumour by a radiologist. Thus SAI cannot be related to the degree of the residual pituitary adenoma in the present study.

\section{Conclusion:}

Surgery for pituitary adenoma is safe and improves vision in the vast majority of patients. However, surgery does not rescue pituitary function in most patients, and solely pituitary failure should therefore not give the indication for surgery. Pituitary apoplexy is a strong predictor of pituitary failure and these patients should be given cortisone substitution on admission and on discharge after surgery. Transsphenoidal surgery for NFPAs in experienced hands infrequently creates new SAI, and patients without SAI before surgery can usually be discharged after surgery without cortisone substitutional therapy. 
Early morning p-cortisol $>168 \mathrm{nmol} / \mathrm{l}(6.1 \mu \mathrm{g} / \mathrm{dl})$ or $\mathrm{p}$-cortisol $\geq 320 \mathrm{nmol} / \mathrm{l}(11.6 \mu \mathrm{g} / \mathrm{dl})$ during SST indicates a sufficient function of the HPA axis. Some patients with an early morning cortisol $<168$ $\mathrm{nmol} / \mathrm{l}(6.1 \mu \mathrm{g} / \mathrm{dl})$ still have a normal response to SST, wherefore SST remains useful.

Funding

No funding was received for this research.

\section{Conflict of Interest}

All authors certify that they have no affiliations with or involvement in any organization or entity with any financial interest (such as honoraria; educational grants; participation in speakers' bureaus; membership, employment, consultancies, stock ownership, or other equity interest; and expert testimony or patent-licensing arrangements), or non-financial interest (such as personal or professional relationships, affiliations, knowledge or beliefs) in the subject matter or materials discussed in this manuscript.

\section{Ethical approval}

All procedures performed in studies involving human participants were in accordance with the ethical standards of the institutional and/or national research committee (name of institute/committee) and with the 1964 Helsinki declaration and its later amendments or comparable ethical standards.

\section{Informed consent}

Informed consent was obtained from all individual participants included in the study.

\section{References}

1. Abdu TAM, Elhadd TA, Neary R, Clayton RN (1999) Comparison of the Low Dose Short Synacthen Test $(1 \mu \mathrm{g})$, the Conventional Dose Short Synacthen Test $(250 \mu \mathrm{g})$, and the Insulin Tolerance Test for Assessment of the Hypothalamo-Pituitary-Adrenal Axis in Patients with Pituitary Disease. The Journal of Clinical Endocrinology \& Metabolism 84(3):838-843

2. Agustsson $T T$, Baldvinsdottir T, Jonasson JG, Olafsdottir E, Steinthorsdottir V, Sigurdsson $G$, Thorsson AV, Carroll PV, Korbonits M, Benediktsson R (2015) The epidemiology of pituitary adenomas in Iceland, 1955-2012: a nationwide population-based study. European Journal of Endocrinology 173(5):655-664 
3. Ajlan A, Almufawez KA, Albakr A, Katznelson L, Harsh GR (2018) Adrenal Axis Insufficiency After Endoscopic Transsphenoidal Resection of Pituitary Adenomas. World Neurosurgery 112:e869e875

4. Barker FG, Klibanski A, Swearingen B (2003) Transsphenoidal Surgery for Pituitary Tumors in the United States, 1996-2000: Mortality, Morbidity, and the Effects of Hospital and Surgeon Volume. J Clin Endocrinol Metab 88(10):4709-4719

5. Briet C, Salenave S, Bonneville J-F, Laws ER, Chanson P (2015) Pituitary Apoplexy. Endocr Rev 36(6):622-645

6. Caputo C, Sutherland T, Farish S, McNeill P, Ng KW, Inder WJ (2013) Gender differences in presentation and outcome of nonfunctioning pituitary macroadenomas. Clinical Endocrinology 78(4):564-570

7. Charmandari E, Nicolaides NC, Chrousos GP (2014) Adrenal insufficiency. The Lancet 383(9935):2152-2167

8. Chen L, White WL, Spetzler RF, Xu B (2011) A prospective study of nonfunctioning pituitary adenomas: presentation, management, and clinical outcome. J Neurooncol 102(1):129-138

9. Dallapiazza RF, Grober Y, Starke RM, Laws ER, Jane JA (2015) Long-term Results of Endonasal Endoscopic Transsphenoidal Resection of Nonfunctioning Pituitary Macroadenomas. Neurosurgery 76(1):42-53

10. Dekkers OM, van der Klaauw AA, Pereira AM, Biermasz NR, Honkoop PJ, Roelfsema F, Smit JWA, Romijn JA (2006) Quality of Life Is Decreased after Treatment for Nonfunctioning Pituitary Macroadenoma. The Journal of Clinical Endocrinology \& Metabolism 91(9):3364-3369

11. Dekkers OM, Pereira AM, Roelfsema F, Voormolen JHC, Neelis KJ, Schroijen MA, Smit JWA, Romijn JA (2006) Observation Alone after Transsphenoidal Surgery for Nonfunctioning Pituitary Macroadenoma. J Clin Endocrinol Metab 91(5):1796-1801

12. Dekkers OM, Pereira AM, Romijn JA (2008) Treatment and Follow-Up of Clinically Nonfunctioning Pituitary Macroadenomas. J Clin Endocrinol Metab 93(10):3717-3726

13. Fatemi N, Dusick JR, Mattozo C, McArthur DL, Cohan P, Boscardin J, Wang C, Swerdloff RS, Kelly DF (2008) Pituitary hormonal loss and recovery after transsphenoidal adenoma removal. Neurosurgery 63(4):709-719

14. Fernandez-Rodriguez E, Lopez-Raton M, Andujar P, Martinez-Silva IM, Cadarso-Suarez C, Casanueva FF, Bernabeu I (2013) Epidemiology, mortality rate and survival in a homogeneous population of hypopituitary patients. Clinical Endocrinology 78(2):278-284

15. Filipsson $H$, Monson JP, Koltowska-Häggström M, Mattsson A, Johannsson $G$ (2006) The Impact of Glucocorticoid Replacement Regimens on Metabolic Outcome and Comorbidity in Hypopituitary Patients. J Clin Endocrinol Metab 91(10):3954-3961

16. Freda PU, Beckers AM, Katznelson L, Molitch ME, Montori VM, Post KD, Vance ML (2011) Pituitary Incidentaloma: An Endocrine Society Clinical Practice Guideline. J Clin Endocrinol Metab 96(4):894-904 
17. Gonzálbez, Villabona, Ramón, Navarro, Giménez, Ricart, Soler (2000) Establishment of reference values for standard dose short synacthen test $(250 \mu \mathrm{g})$, low dose short synacthen test $(1 \mu \mathrm{g})$ and insulin tolerance test for assessment of the hypothalamo-pituitary-adrenal axis in normal subjects. Clinical Endocrinology 53(2):199-204

18. Greenman Y, Ouaknine G, Veshchev I, Reider-Groswasser II, Segev Y, Stern N (2003) Postoperative surveillance of clinically nonfunctioning pituitary macroadenomas: markers of tumour quiescence and regrowth. Clinical Endocrinology 58(6):763-769

19. Halvorsen H, Ramm-Pettersen J, Josefsen R, Rønning P, Reinlie S, Meling T, Berg-Johnsen J, Bollerslev J, Helseth E (2014) Surgical complications after transsphenoidal microscopic and endoscopic surgery for pituitary adenoma: a consecutive series of 506 procedures. Acta Neurochir 156(3):441-449

20. Hammarstrand C, Ragnarsson O, Hallén T, Andersson E, Skoglund T, Nilsson AG, Johannsson G, Olsson DS (2017) Higher glucocorticoid replacement doses are associated with increased mortality in patients with pituitary adenoma. European Journal of Endocrinology 177(3):251256

21. Jahangiri A, Wagner JR, Pekmezci M, Hiniker A, Chang EF, Kunwar S, Blevins L, Aghi MK (2013) A Comprehensive Long-term Retrospective Analysis of Silent Corticotrophic Adenomas vs Hormone-Negative Adenomas. Neurosurgery 73(1):8-18

22. Klose M, Lange M, Kosteljanetz M, Poulsgaard L, Feldt-Rasmussen U (2005) Adrenocortical insufficiency after pituitary surgery: an audit of the reliability of the conventional short synacthen test. Clinical Endocrinology 63(5):499-505

23. Lindholm J, Kehlet $\mathrm{H}$ (1987) Re-evaluation of the clinical value of the $30 \mathrm{~min}$ ACTH test in assessing the hypothalamic-pituitary-adrenocortical function. Clinical Endocrinology 26(1):5359

24. Mayenknecht J, Diederich S, Bähr V, Plöckinger U, Oelkers W (1998) Comparison of Low and High Dose Corticotropin Stimulation Tests in Patients with Pituitary Disease. J Clin Endocrinol Metab 83(5):1558-1562

25. Nomikos P, Ladar C, Fahlbusch R, Buchfelder M (2004) Impact of primary surgery on pituitary function in patients with non-functioning pituitary adenomas - a study on 721 patients. Acta Neurochir 146(1):27-35

26. Puar THK, Stikkelbroeck NMML, Smans LCCJ, Zelissen PMJ, Hermus ARMM (2016) Adrenal Crisis: Still a Deadly Event in the 21st Century. The American Journal of Medicine 129(3):339.e1339.e9

27. Regal M, Páramo C, Sierra JM, García-Mayor RV (2001) Prevalence and incidence of hypopituitarism in an adult Caucasian population in northwestern Spain. Clinical Endocrinology 55(6):735-740

28. Tjörnstrand A, Gunnarsson K, Evert M, Holmberg E, Ragnarsson O, Rosén T, Filipsson Nyström H (2014) The incidence rate of pituitary adenomas in western Sweden for the period 2001-2011. European Journal of Endocrinology 171(4):519-526

29. Tomlinson J, Holden N, Hills R, Wheatley K, Clayton R, Bates A, Sheppard M, Stewart P (2001) Association between premature mortality and hypopituitarism. The Lancet 357(9254):425-431 
30. Webb SM, Rigla M, Wägner A, Oliver B, Bartumeus F (1999) Recovery of Hypopituitarism after Neurosurgical Treatment of Pituitary Adenomas. The Journal of Clinical Endocrinology \& Metabolism 84(10):3696-3700

31. Wei L, MacDonald TM, Walker BR (2004) Taking Glucocorticoids by Prescription Is Associated with Subsequent Cardiovascular Disease. Annals of Internal Medicine 141(10):764 
Table 1: Baseline characteristics.

\begin{tabular}{|l|l|}
\hline Male/female & $65 / 52$ \\
\hline Age (mean \pm SD) & $59 \pm 14.7$ years \\
\hline $\begin{array}{l}\text { Largest tumour diameter (mean } \pm \text { SD) } \\
\text {-transsphenoidal surgery } \\
\text {-transcranial surgery }\end{array}$ & $\begin{array}{l}26.8 \pm 8.2 \mathrm{~mm} \text { (range } 13-61 \mathrm{~mm}) \\
26.1 \pm 6.8 \mathrm{~mm}\end{array}$ \\
\hline $\begin{array}{l}\text { Patients with preoperative secondary } \\
\text { adrenal insuffiency }\end{array}$ & $20 / 117(17 \%)$ \\
\hline $\begin{array}{l}\text { Patients with any preoperative } \\
\text { pituitary failure }\end{array}$ & $83 / 117(71 \%)$ \\
\hline $\begin{array}{l}\text { Number of pituitary axes with } \\
\text { preoperative failure }\end{array}$ & 131 (mean per patient: $1.1 \pm 1.0$, range $0-4)$ \\
\hline Visual impairment preoperatively & $99(84.6 \%)$ \\
\hline Transsphenoidal surgery & 114 (97.4\%) \\
\hline Median duration of follow up: & 33 months (range 8-54) \\
\hline
\end{tabular}

Table 1 SD: standard deviation. 
Table 2: Complications related to surgery

\begin{tabular}{|l|l|}
\hline DI early postoperativly & $12 \%$ \\
\hline DI, persistent & $5 \%$ \\
\hline Haemorrhage & $3 \%$ \\
\hline Pneumonia & $3 \%$ \\
\hline
\end{tabular}

Table 3 DI: diabetes insipidus. 
Table 3. Patients characteristics with and without SAI pre- and postoperatively.

\begin{tabular}{|c|c|c|c|c|c|c|}
\hline & \multicolumn{2}{|c|}{ Preoperatively } & & \multicolumn{2}{|c|}{3 months postoperatively } & \\
\hline & SAI $(n=20)$ & $\begin{array}{l}\text { No SAl } \\
(\mathrm{n}=97)\end{array}$ & & SAI $(n=17)$ & No SAI $(n=100)$ & \\
\hline Age (years) & $63.3 \pm 16.4$ & $57.7 \pm 14.3$ & $P=0.123$ & $60.9 \pm 20.9$ & $58.2 \pm 13.5$ & $p=0.494$ \\
\hline $\begin{array}{l}\text { Tumour size }(\mathrm{mm}) \\
\text {-TSS }(n=114) \\
\text {-Transcranial }(n=3)\end{array}$ & $\begin{array}{l}26.8 \pm 7.2 \\
\text { None }\end{array}$ & $\begin{array}{l}26.0 \pm 6.7 \\
53.6 \pm 11.8\end{array}$ & $P=0.632$ & $\begin{array}{l}26.5 \pm 7.5 \\
60.5 \pm 0.7 \\
\end{array}$ & $\begin{array}{l}25.9 \pm 6.7 \\
40(n=1)\end{array}$ & $P=0.818$ \\
\hline Females & $35.0 \%$ & $46.4 \%$ & $p=0.351$ & $41.2 \%$ & $45.0 \%$ & $p=0.769$ \\
\hline $\begin{array}{l}\text { Pituitary axes with } \\
\text { failure }\end{array}$ & $2.1 \pm 1.0$ & $0.9 \pm 0.8$ & $p<0.001$ & $2.5 \pm 1.2$ & $0.7 \pm 0.8$ & $p<0.001$ \\
\hline
\end{tabular}

Table 3 Numbers given as mean \pm SD. P -values indicate comparison between patients with and without secondary adrenal insufficiency (SAI). Transsphenoidal surgery (TSS). 
Table 4. P-cortisol response to Synacthen test three months postoperatively

\begin{tabular}{|l|l|l|l|l|}
\hline & $0 \min$ & $30 \mathrm{~min}$ & $60 \mathrm{~min}$ & Change 0 to 30 \\
\hline No SAl (n=74) & $317.7 \pm 92.0 \mathrm{nmol} / \mathrm{l}$ & $502.5 \pm 98.9 \mathrm{nmol} / \mathrm{l}$ & $418.1 \pm 105.3 \mathrm{nmol} / \mathrm{l}$ & $184.8 \pm 90.5 \mathrm{nmol} / \mathrm{L}$ \\
& $11.5 \pm 3.3 \mu \mathrm{g} / \mathrm{dl}$ & $18.2 \pm 3.6 \mu \mathrm{g} / \mathrm{dl}$ & $15.2 \pm 3.8 \mu \mathrm{g} / \mathrm{dl}$ & $6.7 \pm 3.3 \mu \mathrm{g} / \mathrm{dl}$ \\
\hline SAI $(\mathrm{n}=8)$ & $102.0 \pm 51.4 \mathrm{nmol} / \mathrm{l}$ & $201.2 \pm 73.3 \mathrm{nmol} / \mathrm{l}$ & $156.0 \pm 69.5 \mathrm{nmol} / \mathrm{l}$ & $99.0 \pm 38.9 \mathrm{nmol} / \mathrm{l}$ \\
& $3.7 \pm 1.9 \mu \mathrm{g} / \mathrm{dl}$ & $7.3 \pm 2.7 \mu \mathrm{g} / \mathrm{dl}$ & $5.7 \pm 2.5 \mu \mathrm{g} / \mathrm{dl}$ & $3.6 \pm 1.4 \mu \mathrm{g} / \mathrm{dl}$ \\
\hline
\end{tabular}

Table 4 Only patients given $1 \mu \mathrm{g}$ Synacthen and measured using new assay is included. Values given as mean \pm SD. Secondary adrenal insufficiency (SAI). 
Table 5: Failure of pituitary axes pre- and postoperatively.

\begin{tabular}{|l|l|l|}
\hline & Before surgery & After surgery \\
\hline ACTH & $20 / 109(17.0 \%)$ & $17 / 117(15 \%)$ \\
\hline TSH & $27 / 117(23 \%)$ & $29 / 115(25 \%)$ \\
\hline FSH/LH & $74 / 111(67 \%)$ & $54 / 111(49 \%)$ \\
\hline GH & $9 / 81(11 \%)$ & $7 / 108(7 \%)$ \\
\hline $\begin{array}{l}\text { Diabetes } \\
\text { insipidus }\end{array}$ & $1 / 117(1 \%)$ & $6 / 117(5 \%)$ \\
\hline $\begin{array}{l}\text { Total number } \\
\text { of axes }\end{array}$ & $131 / 535$ (missing 50) & $113 / 564$ (missing 21) \\
\hline $\begin{array}{l}\text { Avg. number } \\
\text { axes with } \\
\text { insufficiency }\end{array}$ & $1.1 \pm 1.0$ & $1.0 \pm 1.1$ \\
\hline
\end{tabular}

Table 5. Number of axis with failure and number of biochemical analyses available. Of 535 axes measured preoperatively, 125 were insufficient, and 50 axes were missing. Postoperatively 113 out of 564 axes were insufficient and 21 were missing. 


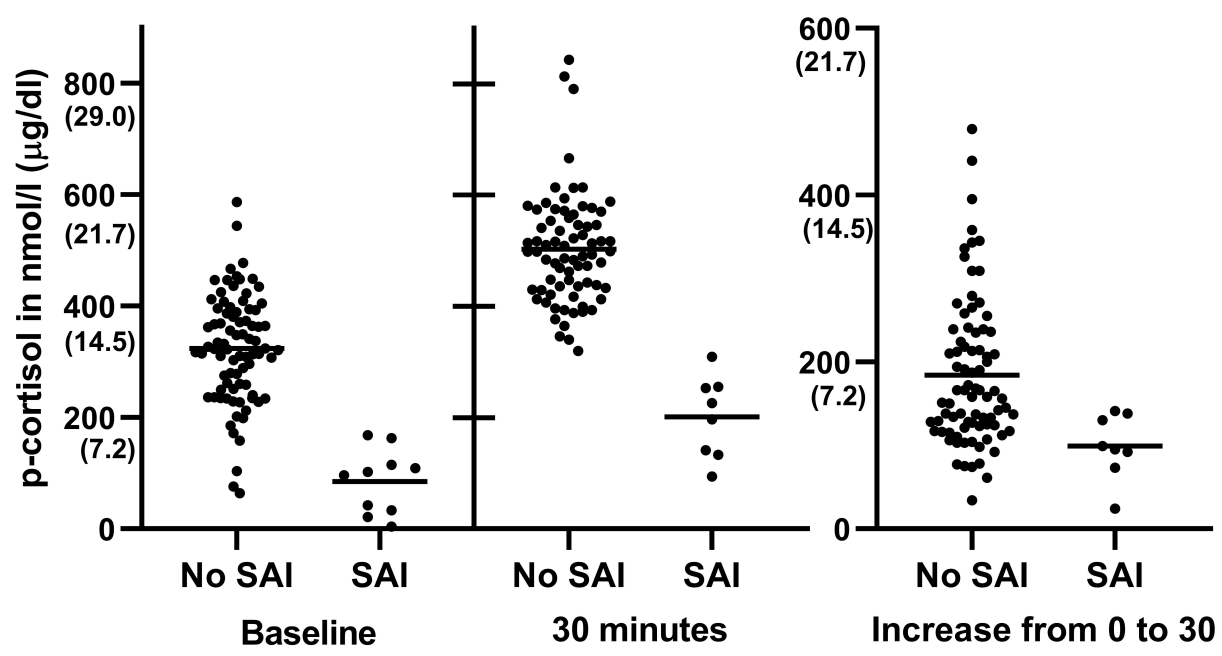

Figure 1 Left panel: P-cortisol values in patients analysed with the new cortisol assay. 92 analyses were available at baseline, of which 10 had SAI. $1 \mu \mathrm{g}$ Short SST was performed in 82 of these patients, of which 8 had SAI. Right panel: Increase in p-cortisol from 0 to 30 minutes during $1 \mu \mathrm{g}$ Short SST in the 82 patients 